\title{
Biologically active fungi of the genus Trichoderma as a perspective means of environmentally safe plant protection
}

\author{
Liliya Khalikova ${ }^{1 *}$, Natalia Borovkova ${ }^{2}$, Oksana Semkina², and Evgeniy Korchikov ${ }^{1}$ \\ ${ }^{1}$ Korolev National Research University of Samara-city, 1 Academician Pavlova st., Samara-city, \\ 443000, Russia \\ ${ }^{2}$ PF “Tsirulev E.P.”, 2A Komarova st., Privolzhie vil., Samarskaya oblast, 445560, Russia.
}

\begin{abstract}
Antagonism of fungi of the genus Trichoderma and various phytopathogenic fungi was investigated. The strains of the genus Trichoderma, which have potential value for the production of biological products for plant protection, have been identified. The highest fungicidal activity among the tested strains is shown by $\mathrm{T}$. asperellum, which determines the prospects of using this strain as a biofungicide. The investigations were carried out in the research laboratory of the Peasant Farm “Tsirulev E.P.”
\end{abstract}

\section{Introduction}

Improvement of agricultural production and accelerated rates of scientific and technological progress expand the degree of human impact on the biosphere as a whole, and especially on agricultural biocenosis. Intensification of the methods of cultivation of agricultural crops leads to a shift in the balance between microorganisms towards pathogens. Abiotic and biotic factors of the environment can influence many properties of the soil, primarily its biological activity and fertility. Violation of crop cultivation technology, unjustified use of various plant protection products, as well as unfavourable environmental factors can lead to the accumulation of a large complex of pathogenic microbiota in the soil (species of the pp. Fusarium, Ophiobolus, Gibellina, Rhizoctonia, Phomopsis, Verticillium, Rhizopus, Pythium, Alternaria, Cercosporella and others) [1].

Plant residues that get into the soil during harvesting, affected by phytopathogens, are the main sources of accumulation, and consequently result in the infection of plants. The harmfulness of phytopathogenic fungi in soil and on plant residues is reduced by suppressor microorganisms. Suppressor microorganisms include representatives of fungi of the genus Trichoderma and certain species of the genus Penicillium and genus Aspergillus [2].

Due to their unique growth and physiological properties, these fungi play an important role in the formation of microbiocenoses of the rhizosphere and soil, growth and development of plants, and they also play an important role in increasing soil fertility. By

\footnotetext{
* Corresponding author: halikova.lilya@yandex.ru
} 
suppressing the density of the soil phytopathogenic population, saprotrophic fungi increase its suppressiveness [2].

A huge amount of factual material has been accumulated on the use of fungi of the genus Trichoderma as producers of biologically active substances used in agriculture [3-7]. Fungi of the genus Trichoderma produce a series of metabolites that increase plant resistance to phytopathogens. In addition, fungi of the genus Trichoderma secrete enzymes that destroy the cell wall of fungi, with some strains exhibiting hyper parasitism - they actively penetrate with their hyphae inside the hyphae of phytopathogenic fungi and suppress their growth $[8,9]$.

The stimulating effect of fungi of the genus Trichoderma on the growth and development of plants is well known. This is provided by the release of auxins, which are also important in the direct formation of symbiotic relations between the fungus and the plant, regulation of the activity of a number of enzymes, and the synthesis of secondary metabolites by the fungus. However, the ability to synthesize auxins in different species varies by tens and hundreds of times [10].

In addition to choosing a biocontrol agent and studying its ability to synthesize enzymes or toxins that affect the productivity of plant growth and protection, it is necessary to select correctly the optimal composition of the nutrient medium for the cultivation of biological agents. It is the composition of the nutrient medium that affects the metabolism of microorganisms, increasing the yield of various compounds [11].

\section{Materials and methods}

One of the components of the comprehensive monitoring of the soil cover is the microbiological assessment of the state of the soils of the studied territories. In this case, researchers, as a rule, determine the number of pathogenic microorganisms and their antagonists [12].

All strains (Trichoderma asperellum, Trichoderma crassum, Trichoderma arundinaceum) where extracted from the soil and identified by type/sort, using Ribosome gene order conservation analysis in the Kurchatov National Research Center.

Research objects: phytopathogens - Alternaria sp., Phoma sp. (IV hazard class), Colletotrichum coccodes; antagonists (IV hazard class) - Trichoderma asperellum, Trichoderma crassum, Trichoderma arundinaceum [13].

All strains of antagonists and phytopathogens were isolated from the soil by the serial dilution method $[14,15]$. Soil sampling was carried out directly in the fields of the farm, in accordance with the methods of sampling and preparation of samples for chemical, bacteriological, helminthological analysis [16].

Identification of antagonist strains to a species based on analysis of the sequence of ribosomal genes was carried out at the Kurchatov National Research Center.

Preparation of potato glucose agar includes the following steps: $200 \mathrm{~g}$ of washed, peeled and sliced potatoes were placed into $1000 \mathrm{ml}$ of distilled water and boiled for 40 minutes, then filtered. Water is added to the filtered liquid to $1000 \mathrm{ml}$ and $20 \mathrm{~g}$ of agar-agar and $20 \mathrm{~g}$ of glucose are added and heated until the agar is completely melted [17].

Determination of antagonistic properties was carried out by the method of agar blocks. On the surface of dense potato-glucose agar in vitro, discs of phytopathogen and antagonist cultures were applied from two opposite sides (Fig. 1) [18]. 


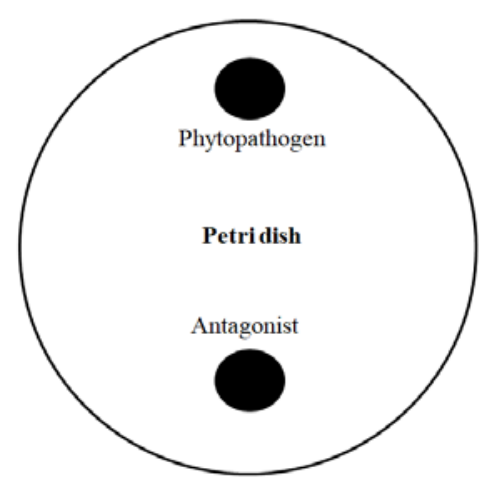

Fig. 1. Scheme of the experiment

The dishes were incubated in a thermostat under the conditions required for these types of cultures $-25^{\circ} \mathrm{C}$, aerobically, for 14 days.

\section{Results and discussion}

Possible antagonistic activity was determined by the presence of the zone of inhibition of the growth of the phytopathogen culture, or by the manifestation of hyperparasitism by the antagonist.

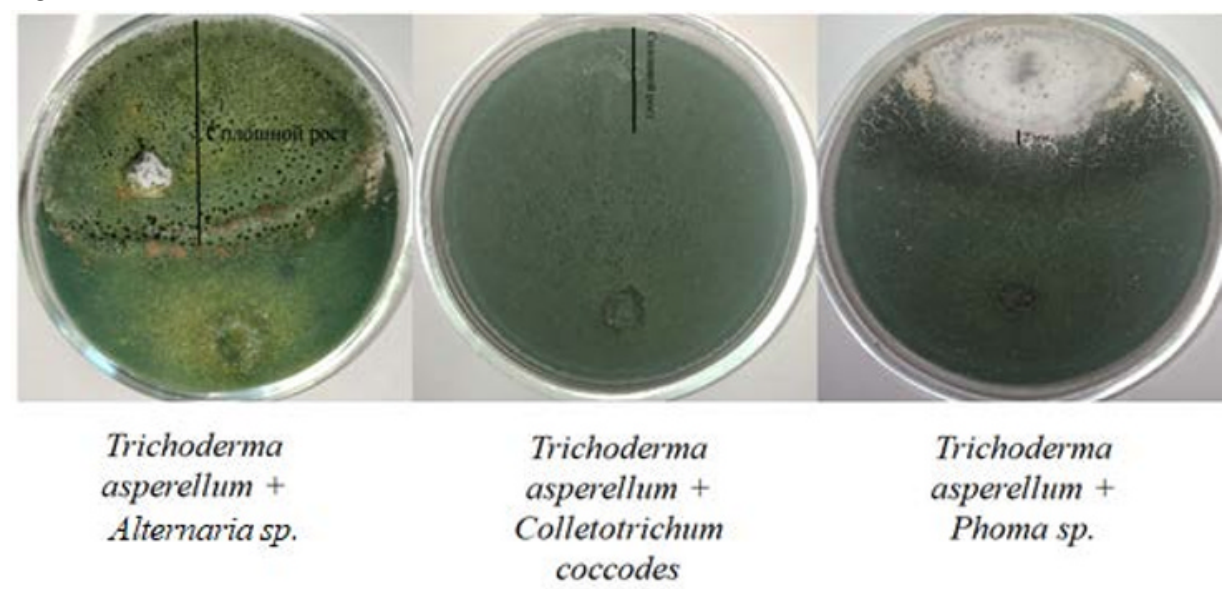

Fig. 2. Antagonistic activity of the fungus Trichoderma asperellum relative to some phytopathogenic microorganisms

The investigation of the antagonistic activity of the fungus Trichoderma asperellum showed a high degree of hyperparasitism against the phytopathogens Alternaria sp. and Colletotrichum coccodes. Intense inhibition is observed in a Petri dish with a culture of the phytopathogen Phoma sp. (Fig. 2). 


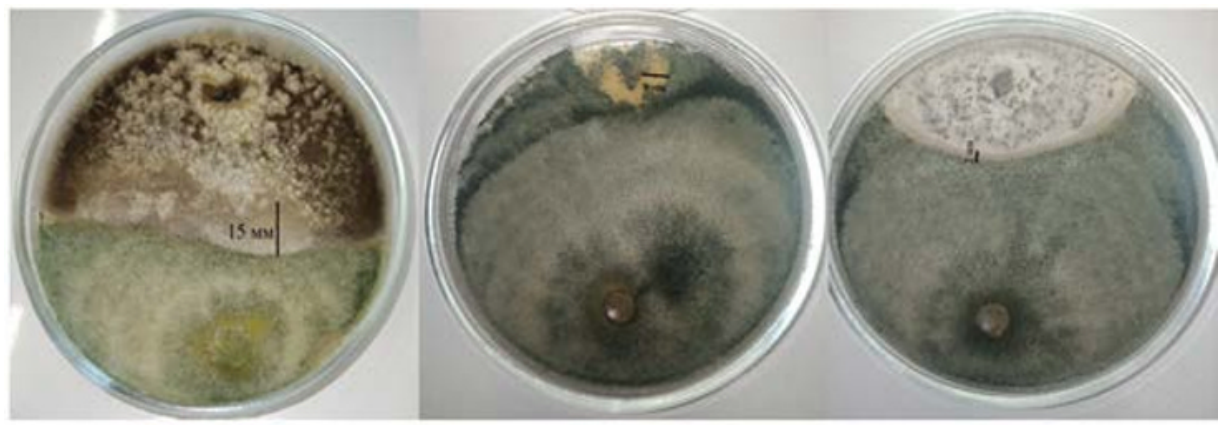

$\begin{array}{ccc}\text { Trichoderma crassum }+ & \text { Trichoderma crassum }+ & \text { Trichoderma crassum }+ \\ \text { Alternariasp } & \text { Colletotrichum coccodes } & \text { Phoma sp. }\end{array}$

Fig. 3. Antagonistic activity of the fungus Trichoderma crassum against some phytopathogenic microorganisms

The largest zone of antagonistic activity of the fungus Trichoderma crassum is observed in experiments with Alternaria sp. and Phoma sp. The phenomenon of hyperparasitism was noted in relation to the Colletotrichum coccodes culture (Fig. 3).

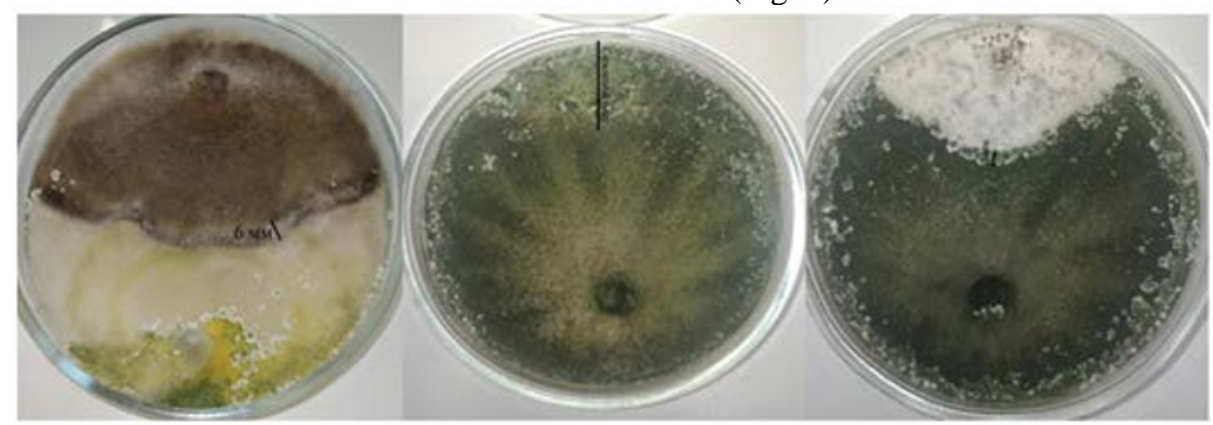

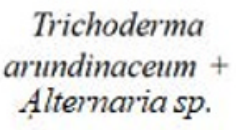

Trichoderma Alternariasp.

\section{Trichoderma arundinaceum + Colletotrichum coccodes}

Trichoderma arundinaceum + Phoma sp.

Fig. 4. Antagonistic activity of the fungus Trichoderma arundinaceum relative to some phytopathogenic microorganisms

The hyperparasitic activity of Trichoderma arundinaceum is observed in the experiment with Colletotrichum coccodes. In relation to other types of phytopathogens, a weak antagonistic effect was revealed (Fig. 4).

Analyzing the results obtained, it can be seen that of all the declared antagonists, only the Trichoderma asperellum strain exhibits mycoparasitic antagonism against two phytopathogenic fungi - Alternaria sp. and Colletotrichum coccodes. These antagonists colonize the pathogen cultures as a result of competition for nutrient sources. The strains of Trichoderma arundinaceum and Trichoderma crassum show their antagonistic properties differently.

The largest zone of suppression of the growth of phytopathogens is shown by Trichoderma crassum and Trichoderma arundinaceum relative to Alternaria sp.; in relation to the culture of Colletotrichum coccodes, these antagonist strains exhibit an identical antagonism character - mycoparasitic. This method of antagonistic activity is most likely 
associated with the manifestation of antibiotic properties against phytopathogens, which proves the presence of biologically active substances in fungi of the genus Trichoderma. It should be noted that in relation to the Phoma sp. all investigated strains show the weakest antagonistic effect.

Thus, the main mechanisms of biocontrol of phytopathogens by antagonists, which include the studied species, include competition for ecological niches, food sources, and production of substances of an antibiotic nature.

For the production of biological products, the selected antagonist microorganism strain must have a complex of characteristics: good survival rate and adaptation to the conditions of the rhizosphere of plants and those ecosystems in which it will be used. For open agrocenoses, the strain should have a wide range of optimal parameters for its development - $\mathrm{pH}$, temperature and humidity [19]. This is a further direction in the study of the properties of the strains Trichoderma asperellum, Trichoderma crassum, Trichoderma arundinaceum.

\section{Conclusions}

Fungi of the genus Trichoderma and some phytopathogens were isolated from the soil and identified. The study determined experimentally the biologically active substances that exhibit its properties against the most common pathogens of agricultural plant diseases Alternaria sp., Phoma sp. and Colletotrichum coccodes. It was found that the strain of Trichoderma asperellum has the greatest antagonistic and hyperparasitic activity.

Against Alternaria sp. it is more expedient to use the Trichoderma asperellum strain, and against Colletotrichum coccodes, all the antagonist strains showed the same mycoparasitic effect. However, against Phoma sp. other antagonist strains should be sought.

This work was carried out as part of a comprehensive scientific and technical project "Development of breeding and seed production of potatoes in the Samara region."

\section{References}

1. J. Stancheva. Atlas of crop diseases. 4, 186 p. (2003).

2. E.Yu. Kuchmina, F.K. Alimova, S.N. Kiyamova. The influence of Trihoderma harzianum on the toxic and mutagenic properties of the soil Abstracts of the report, pp. 30-31. (2001).

3. N.Yu. Gromova, Yu.Yu. Kosivtsov, E.M. Sulman. Technology of synthesis and biosynthesis of biologically active substances, 84p. (2006).

4. F.K. Alimova, D.I. Tazetdinova, R.I. Tukhbatova. Industrial application of fungi of the genus Trichoderma, 234 p. (2007).

5. A.D. Burakaeva. Mycophilic fungi in the biotechnology of fungicidal preparations. Bull. of the OSU, 6, pp. 98-103. (2014).

6. I.A. Gneusheva, N.E. Pavlovskaya, I.V. Yakovleva Biological activity of fungi of the genus Trichoderma and their industrial application. BO GAU 3, p. 36-39. (2010).

7. L.T. Hoang. Biological activity of liquid preparation Trichoderma in in vivo and in vitro experiments. Bas. Res. 1, p. 59-65. (2011).

8. V.A. Tyulpanova, T.I. Gromovykh, A.L. Malinovsky Biotechnology of new forms of fungal fungicides for plant protection. Sib. Ecol. J. 5, pp. 495 - 500. (1977) 
9. P.A. Sychev, Yu.A. Shaposhnik. Antagonistic properties of Trichoderma viride Fr. in relation to some pathogens Cucumis sativum L. Mikol. and phytopathol 16, pp.151159. (1982).

10. I.V. Struchkova. Microscopic fungi Trichoderma virens are promising producers of auxin in mycorrhizal communities. Biology. Bull. of the NNU. 3, pp. 114-118. (2014).

11. V.A. Chkhenkeli, G.D. Chkhenkeli, E.A. Agapova. Some aspects of biomedical research of higher wood-destroying basidiomycetes as a source of biologically active substances. Sib. honey. Mag. 1, pp. 59-65. (2001).

12. I.A. Sakhabiev, S.S. Ryabichko, V.V. Ivanova, A.A. Akhmed, B.R. Grigoryan, F.K. Alimova. Monitoring of micromycetes of leached chernozem of agrocenoses of the Cheremshansk region of the Republic of Tatarstan. Scientist. app. Kazan. un-that, 153, 2, pp. 250-261. (2011).

13. Sanitary and Epidemiological Rules SP 1.3.2322-08. Safety of work with microorganisms of III-V pathogenicity (danger) groups and pathogens of parasitic diseases. http://docs.cntd.ru/document/902091086

14. M.A. Litvinov. Methods of studying soil microscopic fungi (Leningrad: Nauka), 123 p. (1969).

15. O.V. Kuzina, O.N. Smirnva Microbiological methods for studying environmental objects, 14 p. (2013).

16. State Standart GOST 17.4.4.02-2017. Nature Conservancy (SSOP). Soils. Methods of sampling and preparation of samples for chemical, bacteriological, helminthological analysis. http://docs.cntd.ru/document/1200158951

17. A.P. Astashkina. Preparation of nutrient media and cultivation of microorganisms: guidelines for laboratory work in the disciplines "Microbiology", "Pharmacology, biochemistry, microbiology" and "Biotechnology" for full-time students of IPR, IPHT (Tomsk: TPU), 19 p. (2015).

18. V.V. Lysak, R.A. Zheldakova. Microbiology: methodological recommendations for laboratory studies and control of students' independent work (Minsk: BSU), 100p. (2002).

19. A.N. Likhachev, V. Sadykova SinceEstablishment of a complex of traits - tests for the selection of anatagonists for biocontrol of phytopathogens (by the example of fungi of the genus Trichoderma. UNR, 16, pp. 33-47. (2007). 